\title{
JNPH
}

Volume 7 No. 2 (Oktober 2019)

(C) The Author(s) 2019

\section{PENGARUH KEPADATAN HUNIAN RUMAH DENGAN KEJADIAN TB PARU DI WILAYAH KERJA PUSKESMAS BASUKI RAHMAD KOTA BENGKULU TAHUN 2019}

\section{THE INFLUENCE OF HOUSEHOLD DENSITY WITH THE EVENT OF LUNG TB IN THE WORKING AREA OF PUSKESMAS BASUKI RAHMAD IN BENGKULU CITY 2019}

\author{
FIYA DINIARTI, EPINA FELIZITA, HASANUDIN \\ FIKES UNIVED BENGKULU \\ Email: Fiyadiniarti@yahoo.co.id
}

\begin{abstract}
ABSTRAK
Latar Belakang: TB Paru telah membunuh 1,5 juta orang. 58\% kasus TB dunia diantaranya terdapat di Asia Tenggara dan Pasifik Barat. Indonesia menempati posisi terbesar kedua kasus TB setelah India (23\%) yaitu sebesar 10\%. Di Indonesia, diperkirakan prevalensi TB untuk semua tipe TB adalah 505.614 kasus per tahun, 244 per 10.000 penduduk dan 1447 per hari. Insidensi kasus baru 236.029 per tahun, 102 kasus per 10.000 penduduk, dan 647 per hari. Insidensi kasus TB yang mengakibatkan kematian 91.369 per tahun, 30 kasus per 1000 penduduk, dan 250 per hari dalam. Tujuan penelitian ini adalah untuk mengetahui analisis determinan kejadian TB Paru. Metode penelitian : Jenis penelitian ini adalah penelitian kuantitatif dengan desain case control study. Data dikumpulkan dengan menyebarkan kuesioner pada 40 responden TB Paru (BTA +) dan 40 responden TB Paru (BTA -) di Wilayah Kerja Puskesmas Basuki Rahmad Kota Bengkulu. Teknik pengambilan sampel simple random sampling.Hasil Penelitian : Sebagian besar responden pada kelompok kasus memiliki kepadatan hunian yang tidak memenuhi syarat ( $>2$ orang per $8 \mathrm{~m}^{2}$ ). Hasil analisis bivariat ada hubungan antara kepadatan hunian dengan kejadian TB Paru $p(0,007)$.Saran : Disarankan kepada pihak Dinas Kesehatan dan Puskesmas Basuki Rahmad Kota Bengkulu untuk melakukan deteksi dini TB Paru dan promosi kesehatan mengenai TB Paru secara kontinu dan berkelanjutan agar pengetahuan masyarakat mengenai TB Paru (penularan, pencegahan, dan pengobatan) dapat meningkat dan mengurangi resiko penyakit TB Paru.
\end{abstract}

Kata Kunci : Tuberkolosis, Kepadatan Hunian

\begin{abstract}
Background: Pulmonary TB has killed 1.5 million people. $58 \%$ of the world's TB cases are found in Southeast Asia and the Western Pacific. Indonesia occupies the second largest position of TB cases after India (23\%), which is $10 \%$. In Indonesia, the estimated prevalence of TB for all types of TB is 505,614 cases per year, 244 per 10,000 population and 1447 per day. The incidence of new cases is 236,029 per year, 102 cases per 10,000 population, and 647 per day. The incidence of TB cases resulting in 91,369 deaths per year, 30 cases per 1000 population, and 250 per day in. The purpose of this study was to determine the determinant analysis of
\end{abstract}


pulmonary TB events. esearch methods: This research is a quantitative study with a case control study design. Data were collected by distributing questionnaires to 40 respondents of pulmonary TB $(\mathrm{BTA}+)$ and 40 respondents of pulmonary TB (BTA -) in the working area of Basuki Rahmad Public Health Center in Bengkulu City. Simple random sampling technique.

esults: The majority of respondents in the case group had occupancy densities that did not meet the requirements $(>2$ people per $8 \mathrm{~m} 2)$. The results of bivariate analysis have a relationship between the density of occupancy and the incidence of pulmonary TB (0.007). Suggestion: It is recommended to the Health Office and Puskesmas Basuki Rahmad Bengkulu City to conduct early detection of pulmonary $\mathrm{TB}$ and health promotion on pulmonary TB continuously and continuously so that public knowledge about pulmonary TB (transmission, prevention, and treatment) can increase and reduce the risk of TB disease Lungs

\section{Keywords: Tuberculosis, Household Density}

\section{PENDAHULUAN}

Penyakit Tuberkulosis (TB) adalah penyakit menular langsung yang disebabkan oleh kuman Mycobacterium tuberculosis. Sebagian besar kuman TB menyerang paru, tetapi dapat juga menyerang organ lain, seperti selaput otak, tulang, kelenjar getah bening, dan lainnya. Sumber penularan adalah penderita TB Paru yang dapat menular kepada orang lain disekelilingnya terutama yang melakukan kontak lama. Setiap satu penderita akan menularkan pada $10-15$ orang pertahun (Kemenkes, 2015).

Diperkirakan seorang pasien TB Paru dewasa akan kehilangan rata-rata waktu kerjanya tiga sampai empat bulan. Hal tersebut berakibat pada kehilangan pendapatan tahunan rumah tangganya sekitar dua puluh sampai tiga puluh persen. Selain merugikan secara ekonomis, TB juga memberikan dampak buruk lainnya secara sosial stigma bahkan dikucilkan oleh masyarakat (Panjaitan, F, 2012).

Menurut Rye (2016) bahwa ada 22 negara dengan kategori beban tertinggi terhadap TB Paru. Sekitar $80 \%$ penderita TB Paru di dunia berada pada 22 negara berkembang dengan angka kematian 3 juta setiap tahunnya dari 9 juta kasus baru dan secara global angka insidensi penyakit TB Paru meningkat $1 \%$ setiap tahun.

TB Paru merupakan permasalahan kesehatan global yang telah menjadi perhatian dunia selama 2 dekade terakhir. TB Paru telah membunuh 1,5 juta orang. WHO memperkirakan terdapat 9,6 juta kasus TB Paru pada tahun 2014 namun hanya 6 juta kasus yang terlaporkan, artinya terdapat 3,6 juta kasus yang tidak terdiagnosis atau tidak terlaporkan. Sementara itu, 58\% kasus TB dunia diantaranya terdapat di Asia Tenggara dan Pasifik Barat. Indonesia menempati posisi terbesar kedua kasus TB setelah India (23\%) yaitu sebesar 10\% (WHO, 2015).

Di Indonesia, diperkirakan prevalensi TB untuk semua tipe TB adalah 505.614 kasus per tahun, 244 per 10.000 penduduk dan 1447 per hari. Insidensi kasus baru 236.029 per tahun, 102 kasus per 10.000 penduduk, dan 647 per hari. Insidensi kasus TB yang mengakibatkan kematian 91.369 per tahun, 30 kasus per 1000 penduduk, dan 250 per hari (Kemenkes RI, 20013) dalam (Oktari, 2015).

Masih tingginya angka penyakit TB Paru di Indonesia dipengaruhi oleh beberapa faktor yaitu rendahnya penghasilan, tingkat kepadatan penduduk, tingkat pendidikan, rendahnya pengetahuan kesehatan pada masyarakat, serta sanitasi lingkungan rumah. Sanitasi lingkungan rumah sangat mempengaruhi keberadaan bakteri Mycobacterium tuberkulosis, dimana bakteri Mycobacterium tuberkulosis dapat hidup selama 1-2 jam bahkan sampai beberapa hari hingga berminggu-minggu tergantung ada tidaknya sinar matahari, ventilasi, kelembaban, suhu, dan kepadatan penghuni rumah (Muaz, 2014).

Kepadatan hunian juga erat kaitan 
dengan faktor sosial ekonomi seseorang, karena pendapatan kecil membuat orang tidak dapat hidup layak yang memenuhi syaratsyarat kesehatan. Berdasarkan penelitian yang telah dilakukan oleh mamangkey, 2013 tentang hubungan kepadatan hunian dengan kejadian TB Paru diperoleh nilai $P=(0.000)$ $<\alpha=0,05$ hal ini berarti $H_{0}$ ditolak yang artinya ada hubungan antara kepadatan hunian dengan kejadian TB Paru.

Data yang diperoleh dari profil Dinas Kesehatan Kota Bengkulu, jumlah seluruh kasus TB pada tahun 2016 yaitu sebanyak 538 kasus. Kasus tertinggi terdapat di Puskesmas Basuki Rahmad Kota Bengkulu yaitu 36 kasus, dan terendah terdapat di Puskesmas Sidomulyo dan Kampung Bali yaitu 2 kasus, sedangkan pada tahun 2017 terdapat 633 kasus, kasus tertinggi terdapat di Puskesmas Basuki Rahmad yaitu 68 kasus, dan kasus terendah terdapat di Puskesmas Kuala Lempuing sebanyak 6 kasus. Dilihat dari data tersebut, Kasus TB di Puskesmas Basuki Rahmad mengalami peningkatan pada tahun 2016-2017. (Dinas Kesehatan Kota Bengkulu, 2017).

Data yang diperoleh dari Poli TB Puskesmas Basuki Rahmad Kota Bengkulu, pada tahun 2016 terdapat 36 kasus, yaitu 22 laki-laki dan 14 perempuan, tahun 2017 terdapat 68 kasus yaitu 44 kasus pada lakilaki dan 24 kasus pada perempuan, dan pada tahun 2018 terdapat 64 kasus yaitu 42 kasus pada lai-laki dan 22 kasus pada perempuan.

Dari hasil wawancara yang dilakukan dengan pemegang program TB Paru di Puskesmas Basuki Rahmad, kepadatan hunian rumah pasien TB paru diwilayah kerja puskesmas Basuki Rahmad, dalam satu rumah penghuninya melebihi nilai batas yang tentukan, yaitu 2 orang per $8 \mathrm{~m}^{2}$.

Berdasarkan data dan uraian permasalahan yang ada di Puskesmas Basuki Rahmad, maka penulis tertarik untuk melakukan penelitian yang berjudul "Pengaruh Kepadatan Hunian dengan kejadian TB Paru di Wilayah Kerja Puskesmas Basuki Rahmad Kota Bengkulu tahun 2019".

\section{METODE PENELITIAN}

Jenis penelitian ini adalah observasional analitik dengan rancangan case control. Waktu penelitian pada bulan maret sampai dengan agustus 2019. Populasi kasus pada penelitian sebanyak 64 orang dan tercatat diregister TB01 dengan BTA positif $(+)$ di Poli TB Puskesmas Basuki Rahmad Kota Bengkulu Tahun 2018 dan populasi kontrol sebanyak 67 orang dan tercatat deregister TB01 dengan BTA negative (-) di Poli TB Puskesmas Basuki Rahmad Kota Bengkulu Tahun 2018.

Jumlah Sampel kasus berjumlah 40 orang dan jumlah sampel control berjumlah 40 orang. Sehingga jumlah keseluruhan sampel yang memungkinkan diambil pada penelitian ini adalah 80 sampel, diambil dengan mengunakan tekhnik simple random sampling. Data dalam penelitian ini mengunakan data primer dan sekumder. Pengumpulan data wawancara menggunakan kuesioner. Cara analisa data menggunakan analisis univariat dan bivariate (dengan uji chi-square). Pengolahan data dengan menggunakan computer dilakukan melalui beberapa tahap antara lain: Editing, coding, tabulating, entry data, cleaning dan saving.

\section{HASIL PENELITIAN}

\section{Analisa Univariat}

Analisis univariat digunakan untuk mendapatkan gambaran dari variabel yang diteliti. Variabel independen dalam penelitian ini adalah dan kepadatan hunian, sedangkan variabel dependen adalah kejadian TB paru.

Tabel 1. Distribusi Frekuensi Kepadatan Hunian responden di Wilayah Kerja Puskesmas Basuki Rahmad Kota Bengkulu Tahun 2019

\begin{tabular}{ccccc}
\hline Kepadatan Hunian & \multicolumn{2}{c}{$\begin{array}{c}\text { Kelompok } \\
\text { Kasus }\end{array}$} & \multicolumn{2}{c}{$\begin{array}{c}\text { Kelompok } \\
\text { Kontrol }\end{array}$} \\
\cline { 2 - 5 } & $\mathbf{f}$ & $\mathbf{\%}$ & $\mathbf{f}$ & $\mathbf{\%}$ \\
\hline $\begin{array}{c}\text { Tidak memenuhi syarat } \\
\left(>2 \text { orang per } 8 \mathrm{~m}^{2}\right)\end{array}$ & 28 & 70.0 & 15 & 37.5 \\
\hline
\end{tabular}




\begin{tabular}{ccccc}
\hline $\begin{array}{c}\text { Memenuhi syarat } \\
\left(2 \text { orang per } 8 \mathrm{~m}^{2}\right)\end{array}$ & 12 & 30.0 & 25 & 62.5 \\
\hline Total & 40 & 100.0 & 40 & 100.0 \\
\hline
\end{tabular}

Berdasarkan tabel 1 dapat dilihat bahwa sebagian besar responden pada kelompok kasus memiliki kepadatan hunian yang tidak memenuhi syarat ( $>2$ orang per $8 \mathrm{~m}^{2}$ ) yaitu 28 orang $(70,0 \%)$. Pada kelompok kontrol lebih dari sebagian responden memiliki kepadatan hunian yang memenuhi syarat (2 orang per $8 \mathrm{~m}^{2}$ ) yaitu 25 orang $(62,5 \%)$.

\section{Analisa Bivariat}

Tabel 2. Hubungan Kepadatan Hunian dengan Kejadian TB Paru di Wilayah Kerja Puskesmas Basuki Rahmad Kota Bengkulu Tahun 2019

\begin{tabular}{|c|c|c|c|c|c|c|c|}
\hline \multirow{3}{*}{$\begin{array}{c}\text { Kepadatan } \\
\text { Hunian }\end{array}$} & \multicolumn{4}{|c|}{ Kejadian TB Paru } & \multirow[b]{2}{*}{ Total } & \multirow{3}{*}{$P$} & \multirow{3}{*}{ OR } \\
\hline & \multicolumn{2}{|c|}{$\begin{array}{l}\text { Penderita } \\
\text { TB Paru }\end{array}$} & \multicolumn{2}{|c|}{$\begin{array}{c}\text { Tidak TB } \\
\text { Paru }\end{array}$} & & & \\
\hline & $\mathrm{N}$ & $\%$ & $\mathrm{n}$ & $\%$ & $\mathrm{~N}$ & & \\
\hline $\begin{array}{c}\text { Tidak } \\
\text { memenuhi } \\
\text { syarat }(>2 \\
\text { orang per } 8 \\
\left.\mathrm{~m}^{2}\right)\end{array}$ & 28 & 70.0 & 15 & 37.5 & 43 & 0,007 & 3,9 \\
\hline $\begin{array}{l}\text { Memenuhi } \\
\text { syarat ( } 2 \\
\text { orang per } 8 \\
\left.\mathrm{~m}^{2}\right)\end{array}$ & 12 & 30.0 & 25 & 62.5 & 37 & & \\
\hline Total & 40 & 100.0 & 40 & 100.0 & 80 & & \\
\hline
\end{tabular}

Berdasarkan tabel 2 diketahui bahwa dari 40 orang responden penderita TB paru $(\mathrm{BTA}+)$ terdapat 28 orang responden $(70,0 \%)$ memiliki kepadatan hunian yang tidak memenuhi syarat ( $>2$ orang per $8 \mathrm{~m}^{2}$ ), dan 12 orang responden $(30,0 \%)$ memiliki kepadatan hunian yang memenuhi syarat ( 2 orang per 8 $\mathrm{m}^{2}$ ). Sedangkan dari 40 orang responden Tidak TB Paru (BTA -) 15 orang responden (37,5\%) memiliki kepadatan hunian yang memenuhi syarat ( 2 orang per $8 \mathrm{~m}^{2}$ ), dan 25 orang responden $(62,5 \%)$ memiliki kepadatan hunian yang tidak memenuhi syarat $(>2$ orang per $8 \mathrm{~m}^{2}$ ).
Hasil uji statistik dengan menggunakan uji Chi Square diperoleh nilai $p=0,007$ ( $p<$ $0,05)$, sehingga dapat disimpulkan bahwa ada hubungan yang bermakna antara kepadatan hunian responden dengan kejadian TB paru di Wilayah Kerja Puskesmas Basuki Rahmad Kota Bengkulu tahun 2019.

Hasil uji statistik juga menunjukkan nilai $\mathrm{OR}=3,9$ yang berarti bahwa responden yang memiliki kepadatan hunian yang tidak memenuhi syarat berisiko 3,9 kali untuk menderita penyakit TB Paru dibandingkan dengan responden yang memiliki kepadatan hunian yang memenuhi syarat

\section{PEMBAHASAN}

\section{Analisa Univariat}

Distribusi Frekuensi Kepadatan Hunian Responden pada Kejadian TB Paru di Wilayah Kerja Puskesmas Basuki Rahmad Kota Bengkulu Tahun 2019

Hasil penelitian ini mengatakan bahwa sebagian besar responden pada kelompok kasus memiliki kepadatan hunian yang tidak memenuhi syarat $\left(>2\right.$ orang per $8 \mathrm{~m}^{2}$ ) yaitu 28 orang $(70,0 \%)$. Pada kelompok kontrol lebih dari sebagian responden memiliki kepadatan hunian yang memenuhi syarat (2 orang per $8 \mathrm{~m}^{2}$ ) yaitu 25 orang $(62,5 \%)$. Hasil penelitian ini sejalan dengan penelitian yang telah dilakukan oleh Mawardi (2014), yang menyatakan bahwa $82,6 \%$ penderita TB Paru memiliki kepadatan hunian yang tidak memenuhi syarat.

Kepadatan Penghuni merupakan luas lantai dalam rumah dibagi dengan jumlah anggota keluarga penghuni tersebut. Berdasarkan Dir. Higiene dan Sanitasi Depkes RI 1993, maka kepadatan penghuni dikategorikan menjadi memenuhi standar (2 orang per $8 \mathrm{~m}^{2}$ ) dan kepadatan tinggi (lebih 2 orang per $8 \mathrm{~m}^{2}$ dengan ketentuan anak $<1$ tahun tidak diperhitungkan dan umur 1-10 tahun dihitung setengah) (Mukono, 2005).

Standar untuk perumahan umum pada dasarnya ditujukan untuk menyediakan rumah 
tinggal yang cukup baik dalam bentuk desain, letak dan luas ruangan, serta fasilitas lainnya agar dapat memenuhi kebutuhan keluarga atau dapat memenuhi persyaratan rumah tinggal yang sehat dan menyenangkan. Rumah atau tempat tinggal yang buruk atau kumuh dapat mendukung terjadinya penularan penyakit dan gangguan kesehatan seperti TB Paru (Elisa, 2015).

\section{Analisa Bivariat}

\section{a. Hubungan Kepadatan Hunian dengan Kejadian TB Paru di Wilayah Kerja Puskesmas Basuki Rahmad Kota Bengkulu Tahun 2019}

Perumahan atau pemukiman yang buruk akan menimbulkan masalah kesehatan antara lain penyakit infeksi saluran pernapasan dan TB Paru, perumahan yang sehat harus memenuhi beberapa persyaratan antara lain memenuhi kebutuhan fisiologis, mencegah penularan penyakit, dan mencegah terjadinya kecelakaan (Widoyono, 2008).

Hasil uji statistik dengan menggunakan uji Chi Square diperoleh nilai $p=0,007$ ( $p<$ $0,05)$, yang menunjukkan bahwa ada hubungan yang bermakna antara kepadatan hunian responden dengan kejadian TB paru di Wilayah Kerja Puskesmas Basuki Rahmad Kota Bengkulu tahun 2019. Dari hasil analisis data juga diperoleh hasil bahwa reponden yang memiliki kepadatan hunian yang tidak memenuhi syarat mempunyai resiko 3,889 kali untuk menderita TB Paru dibandingkan dengan reponden yang memiliki kepadatan hunian yang memenuhi syarat $(\mathrm{OR}=3,889$, 95\% CI = 1,533 - 9,868).

Penelitian ini sejalan dengan penelitian yang telah dilakukan oleh Rusnoto, yang menyatakan bahwa ada hubungan yang bermakna antara kepadatan hunian rumah dengan kejadian TB Paru $(\mathrm{OR}=5,983)$. Penelitian juga ini sejalan dengan penelitian yang telah dilakukan oleh (Mamangkey, 2013) dalam (Elisa, 2015) tentang hubungan kepadatan hunian dengan kejadian TB Paru diperoleh nilai $P=(0.000)<\alpha=0,05$ hal ini berarti $\mathrm{H}_{\mathrm{o}}$ ditolak yang artinya ada hubungan antara kepadatan hunian dengan kejadian TB Paru.

\section{KESIMPULAN}

Berdasarkan hasil penelitian, analisis data dan pembahasan tentang Analisis Determinan Kejadian TB Paru di Wilayah Kerja Puskesmas Basuki Rahmad Kota Bengkulu tahun 2019 pada BAB sebelumnya, peneliti menarik kesimpulan sebagai berikut:

1. Sebagian besar responden pada kelompok kasus memiliki kepadatan hunian yang tidak memenuhi syarat ( $>2$ orang per $8 \mathrm{~m}^{2}$ ). Pada kelompok kontrol lebih dari sebagian responden memiliki kepadatan hunian yang memenuhi syarat ( 2 orang per $8 \mathrm{~m}^{2}$ ).

2. Ada hubungan yang bermakna antara kepadatan hunian responden dengan Kejadian TB Paru di Wilayah Kerja Puskesmas Basuki Rahmad Kota Bengkulu.

\section{SARAN}

1. Bagi Dinas Kesehatan dan Puskesmas Basuki Rahmad Kota Bengkulu

Disarankan kepada pihak Dinas Kesehatan dan Puskesmas Basuki Rahmad Kota Bengkulu untuk melakukan deteksi dini TB Paru dan kegiatan promosi kesehatan mengenai TB Paru secara kontinu dan berkelanjutan agar pengetahuan masyarakat mengenai TB Paru (penularan, pencegahan, dan pengonatan) dapat meningkat dan mengurangi resiko penyakit TB Paru.

\section{Bagi Peneliti Selanjutnya}

Diharapkan kepada peneliti lain untuk melakukan penelitian lebih lanjut tentang faktor-faktor lain yang mempengaruhi kejadian TB Paru di Kota Bengkulu dengan menambahkan variabel yang baru, jumlah sampel yang lebih besar dan jenis kualitatif dilakukan untuk mendapatkan hasil yang lebih baik sehingga dapat memperkuat keputusan yang diambil. 


\section{DAFTAR PUSTAKA}

Adelia, dkk. 2017. Faktor-faktor yang Mempengaruhi Tingkat kepatuhan Pasien terhadap Pengobatan Tuberkulosis Paru di Lima Puskesmas Se-Kota Pekanbaru. JOM FK Vol 4 No. 2.

Azhar, K., \& Perwitasari, D. 2013. Kondisi Fisik Rumah dan Perilaku dengan Prevalensi TB Paru di Provinsi DKI Jakarta, Banten, dan Sulawesi. Media Litbangkes, Vol 23(4) : 172-181.

Azzahra, Z. 2017. Faktor-faktor yang Mempengaruhi Kejadian Penyakit Tuberkulosis Paru di Wilayah Kerja Puskesmas Mulyorejo Kecamatan Sunggal Kabupaten Deli Serdang Tahun 2017. Fakultas Kesehatan Masyarakat Universitas Sumatera Utara Medan. Skripsi.

Burhanudin, Arif. 2014. Faktor Risiko Tuberkulosis Paru Anak dan Sebaran Spasial di Kabupaten Banyumas Provinsi Jawa Tengah. Semarang. Skripsi.

Damayanti, D.S. dkk. 2018. Faktor Kejadian Tb Paru di Wilayah kerja Puskesmas Liukang Tupabbiring Kabupaten Pangkep. Volume 4 No.2.

Darmawansyah, Wulandari. 2018. Manajemen Epidemiologi TB Paru. Bengkulu : Elmarkazi.

Dinkes Kota Bengkulu. 2017. Profil Dinas Kesehatan Kota Bengkulu 2017. Bengkulu : Dinkes Kota Bengkulu.

Dotulong, dkk. 2014. Hubungan Faktor Risiko Umur, Jenis Kelamin, dan Kepadatan Hunian dengan Kejadian Penyakit TB Pari di Desa Wori Kecamatan Wori. Jurnal. Volume 3 Nomor 2.

Elisa. 2015. Hubungan Antara Umur, Jenis Kelamin, dan Kepadatan Hunian dengan Kejadian TB Paru pada Pasien Rawat Jalan di Rumah Sakit Umum Daerah Noongan. Fakultas Kesehatan Masyarakat Universitas Sam Ratulangi. Manado. Jurnal.

Fatimah, S. 2008. Faktor Kesehatan Lingkungan Rumah yang Berhubungan dengan Kejadian TB Paru di Kabupaten Cilacap. Tesis. Program Pasca Sarjana Universitas Diponegoro Semarang.

Hidayat, dkk. 2018. Skrining dan Studi Epidemiologi Penyakit Tuberkulosis Paru di Lembaga Pemasyarakatan Kelas II A Kendari Tahun 2017, Vol. 2/No.6.

Irnawati, Ni Made, Iyone ET Siagian, Ronald I Ottay. 2016. Pengaruh Dukungan Keluarga Terhadap Kepatuhan Minum Obat pada Penderita Tuberkulosis di Puskesmas Tuminting. Volume 2 Nomor 1.

Kasiram, Moh. 2008. Metodologi Penelitian. Malang : UIN-Malang Pers.

Kemenkes RI. 2011. Pedoman Nasional Pengendalian Tuberkulosis. Direktorat Jendral Pengendalian Penyakit dan Penyehatan Lingkungan Kementrian Kesehatan RI.

Kemenkes RI. 2015. Tuberkulosis : Temukan Obati Sampai Sembuh. Jakarta : Direktorat jenderal pengendalian Penyakit dan Penyehatan Lingkungan.

Kemenkes RI. 2016. Temukan Obati Sampai Sembuh Tuberkulosis. Jakarta.

Kunoli, F.J. 2013. Pengantar Epidemiologi Penyakit menular : Untuk Mahasiswa Kesehatan Masyarakat. Jakarta : TIM.

Kusuma, Saffira. 2014. Hubungan Kualitas Lingkungan Fisik Rumah dan Kejadian TB Paru di Wilayah Kerja Puskesmas Gondanglegi. Malang, Skripsi.

Kusumayati, A. 2009. Materi Ajar Metodologi Penelitian.Kerangka Teori, Kerangka Konsep dan Hipotesis. Depok : Universitas Indonesia.

Laily, Wahyu Dian, Diana Rombot, Banedictus Lampus. 2015. Karakteristik Pasien Tuberkulosis Paru di Puskesmas Gondanglegi. Malang. Skripsi

Mareta, Reni. 2014. Hubungan Antara Karakteristik Kontak Dengan Adanya Gejala TB Pada Kontak Penderita TB Paru BTA+. Universitas Airlangga, Jurnal.

Masriadi. 2012. Epidemiologi Penyakit Menular. Depok : Rajawali Pers.

Mawardi. 2014. Hubungan Kondisi Fisik 
Rumah dan Kepadatan Hunian dengan Kejadian TB Paru di Wilayah Kerja UPT Puskesmas Dadahup Kecamatan Dadahup Kabupaten Kapuas. Jurnal. Vol 1 No 1.

Muaz, Faris. 2014. Faktor-faktor yang mempengaruhi kejadian Tuberkulosis Paru Basil Tahan Asam Positif di Puskesmas Wilayah kecamatan Serang Kota Serang. Jakarta. Skripsi.

Mundiatun, Daryanto. 2015.Pengelolaan Kesehatan Lingkungan.Yogyakarta : Penerbit Gava Media.

Nizar, Muhammad. 2010. Pemberantasan dan Penanggulangan Tuberkulosis. Yogyakarta : Penerbit Gosyen Publishing.

Notoatmodjo, S. 2010. Metode Penelitian Kesehatan. Jakarta : Rineka Cipta.

Nurhayati, I. 2016. Hubungan Tingkat Pengetahuan Terhadap Minum Obat Anti Tuberkulosis (OAT) Pada Penderita Tuberkulosis Paru di RS Paru Sidawangi, Cirebon, Jawa Barat. Fakultas Kedokteran dan Ilmu Kesehatan UMY : Yogyakarta

Oktari, Y. 2015. Faktor Risiko Kejadian Penyakit TB Paru di Wilayah Kerja Puskesmas Kandang Kota Bengkulu Tahun 2015. Fakultas Ilmu kesehatan Universitas Dehasen Bengkulu. Skripsi.

Orlando, C.M. 2018. Analisa Faktor yang Berhubungan dengan Pengetahuan Pasien TB Paru rencana Pulang Tentang Penyakit TB dan Cara Penanganannya di Ruang Rawat Inap RS DR Sobirin Tahun 2018. Fakultas Ilmu Kesehatan Universitan Dehasen Bengkulu. Skripsi.

Panjaitan, F. 2012. Karakteristik Penderita Tuberkulosis Paru Dewasa Rawat Inap di Rumah Sakit Umum DR. Soedarso Pontianak Periode September-November 2010. Fakultas Kedokteran dan Ilmu Kesehatan Universitas Tanjungpura Pontianak. Skripsi.

Refica, dkk. 2017. Gambaran Pengetahuan dan Sikap Pasien TB Paru Terhadap Upaya Pengendalian TB di Puskesmas Sidomulyo Kota PekanBaru. Vol 4.

Ruswanto, B. 2010. Analisis Spasial Sebaran
Kasus Tuberkulosis Paru ditinjau dari faktor lingkungan dalam dan luar rumah di Kabupaten Pekalongan. Emarang. Universitas Diponegoro. Tesis.

Rye, Awusi, Yusrijal Djam'an Saleh, Yuwono Hadiwijoyo. 2016. Faktor-faktor yang Mempengaruhi Penemuan penderita TB Paru di Kota Palu Provinsi Sulawesi Tengah. Skripsi.

Sari, E.T. 2013. Pengaruh Health Education (HE) Dengan Metode Ceramah Terhadap Pengetahuan Keluarga Tentang Penyakit TB Paru. Fakultas Ilmu Kesehatan UMP. Skripsi.

Sugiyono. 2013. Metode Penelitian Pendidikan Pendekatan Kuantitatif, Kualitatif, dan R\&D. Bandung : Alfabeta. Sumarmi, Artha. 2012. Analisis Hubungan Kondisi Fisik Rumah dengan Kejadian TB Paru BTA Positif di Puskesmas Kota Bumi II, Bukit Kemuning dan Ulak Rengas Kab. Lampung Utara Tahun 2012. Universitas Yarsi. Jakarta. Jurnal.

Swarjana, I Ketut. 2015. Metodologi Penelitian Kesehatan.Andi Offeset. Yogyakarta.

Tulchinsky, T., \& Varavikova, E. 2014. The New Public Health Third Edition. San Diego : Elsevier, Academic Press.

Versitaria, Kusnoputranto. 2011. Tuberkulosis Paru di Palembang, Sumatera Selatan. Jurnal Kesehatan Masyarakat Nasional Vol.5.

WHO. 2013. Nutritional Care and Support for Patients with Tuberculosis. World Health Organization.

WHO. 2015. Globlal Tuberculosis Report 2015. World Health Organization.

Wijaya, A. A. 2012. Merokok dan Tuberkulosis. Jurnal Tuberkulosis Indonesia, Vol 8,18-23.

Zuriya, Y. 2016. Hubungan Antara Faktor Host dan Lingkungan dengan Kejadian TB Paru di Wilayah Kerja Puskesmas Pemulang Tahun 2016. Fakultas Kedokteran dan Ilmu kesehatan Universitas Islam Negeri Syarif Hidayatullah Jakarta. Skripsi. 